\title{
Aortic Valve Neocuspidization Using Autologous Pericardium (Ozaki Procedure): an Alternative to Aortic Valve Replacement in Adult Cardiac Surgery?
}

\author{
Luca Koechlin ${ }^{1}$ (D) $\cdot$ Friedrich S. Eckstein ${ }^{1}$ \\ Accepted: 31 May 2021 / Published online: 6 August 2021 \\ (C) The Author(s) 2021
}

\begin{abstract}
Purpose of the Review The aim of this article is to describe the technique of aortic valve neocuspidization using autologous pericardium (AVNeo, "OZAKI procedure") in adult cardiac surgery, to analyze recent findings, and to discuss benefits and limitations of this technique.

Recent Findings Potential benefits of this technique include excellent hemodynamic performances, minimal use of foreign material, low rates of permanent pacemaker implantation, and omission of oral anticoagulation. However, data regarding the durability of the procedure are hitherto limited, and the procedure is associated with a higher complexity compared to aortic valve replacement.

Summary AVNeo using autologous pericardium in adult cardiac surgery is a promising technique providing several benefits. However, there is a major unmet need for more data, especially regarding long-term durability. Thus, based on currently available data, we recommend careful patient selection within the heart team and shared decision-making with the informed patient.
\end{abstract}

Keywords Aortic valve neocuspidization $\cdot$ OZAKI $\cdot$ Autologous pericardium $\cdot$ Aortic valve replacement

\section{Introduction}

The most common form of heart valve disease is aortic valve stenosis, which is a severe and growing public health problem [1].

Despite major advances in the interventional therapy of aortic valve pathologies and the increased use of transcatheter aortic valve replacement (TAVR), open surgical aortic valve replacement (SAVR) is still recommended in the 2017 European Society of Cardiology (ESC)/European Association for Cardio-Thoracic Surgery (EACTS) Guidelines for the management of valvular heart disease in (a) symptomatic patients with severe aortic stenosis at low surgical risk (STS or EuroSCORE II $<4 \%$ or logistic

This article is part of the Topical Collection on Cardiovascular Anesthesia

Friedrich S. Eckstein

friedrich.eckstein@usb.ch

1 Department of Cardiac Surgery, University Hospital Basel, Spitalstrasse 21, CH-4031 Basel, Switzerland
EuroSCORE I $<10 \%$ and no other risk factors not included in these scores, such as frailty, porcelain aorta, sequelae of chest radiation); in (b) asymptomatic patients with severe aortic stenosis and systolic left ventricular dysfunction or abnormal exercise test showing symptoms on exercise clearly related to aortic stenosis; as well as in (c) patients undergoing coronary artery bypass graft (CABG) surgery or surgery of the ascending aorta or of another valve and (d) patients with specific anatomical features such as severe left ventricular outflow tract calcification [2].

For patients with severe aortic regurgitation, to date, no TAVR prosthesis is certified, and surgery remains the therapy of choice. The decision of whether or not a reconstruction or replacement of the valve should/can be performed mainly depends on the modality of the regurgitation and anatomical facts [2].

The type of aortic valve prosthesis in adults is mainly determined by the risk of anticoagulation-related bleeding and thromboembolism with a mechanical valve versus the risk of structural valve deterioration with a biological prosthesis. It is also affected by the patient's lifestyle and preferences. Therefore, the choice of the informed patient has a Class I/Level $C$ recommendation by the guidelines, whereas crude age limits (mechanical prosthesis for 
patients $<60$ years and bioprosthesis for patients $>65$ years) only have a Class IIa /Level C recommendation [2].

Notwithstanding, the aortic valve replacement (AVR) technique with autologous glutaraldehyde-treated pericardium to rebuild the aortic valve, the so called "OZAKI" procedure (also referred to as "aortic valve neocuspidization, AVNeo"), has gained popularity within the past years [3-17]. The concept of using (autologous) pericardium to reconstruct/rebuild the aortic valve is well known in pediatric cardiac surgery. However, the technique introduced by Ozaki et al. in 2011 provides a highly standardized, detailed, and reproducible operative protocol $[3,18,19]$.

The aim of this article is to describe the AVNeo technique in adults, to analyze recent findings, and to discuss benefits and limitations of this technique.

\section{Search Strategy}

The PubMed database was searched for relevant publications, using the search strings "aortic valve replacement", "aortic valve reconstruction", "aortic valve neocuspidization", "Ozaki”, and "autologous pericardium".

\section{Surgical Technique}

The AVNeo technique using autologous pericardium was described by Ozaki et al. in 2011 [3].

In our institution, the surgery is performed in general anesthesia. According to our routine protocol for patients undergoing open heart surgery, the patient is continuously monitored by 2-lead electrocardiography (II, V5), pulse oximetry, and invasive measurement of arterial blood and central venous pressure by a board-certified cardiac anesthesiologist [5, 14].

Transesophageal echocardiography (TEE) is performed throughout the procedure and is of upmost importance to assess the valve function at the end of the operation.

After median sternotomy, the pericardium is dissected, sutured to a hole-plate to prevent shrinking, and cleansed from fatty and connective tissue. Consecutively, it is treated with a $0.6 \%$ glutaraldehyde solution for $10 \mathrm{~min}$ before it is rinsed 3 times for $6 \mathrm{~min}$ with sterile saline [4, 20]. In the meantime, the ascending aorta and the right atrium are cannulated, and cardiopulmonary bypass is established after heparinization. After aortotomy, the diseased cusps are meticulously resected. The distance between each commissure is measured using a special sizer. The pericardium is subsequently cut using a template that corresponds to the previously measured size. At this point, the varying thickness of the pericardium has to be considered. The pericardium is usually thicker in vicinity of the diaphragm than in the area of the aortic root. Thus, the larger cusps are usually taken from the diaphragmatic area.
Moreover, the inner side of the pericardium (serous lamina) is smoother, wherefore this side faces to the ventricle. The cusps are then sewn along the annuli with a 4-0 running suture, and commissural coaptation is secured with additional 40 sutures. All sutures are knotted and reinforced with an autologous patch outside the aorta. The functionality of the substituted valve is intraoperatively reassessed by TEE after declamping. A pericardial patch (bovine pericardium or PTFE) is used to replace the autologous pericardium. In our institution, the patients are postoperatively routinely monitored on the intensive care unit, and lifelong anti-platelet therapy is prescribed (100 $\mathrm{mg}$ aspirin/day) [5, 14•].

In order to reduce the surgical trauma, efforts have been made to perform the procedure minimally invasive. To harvest the pericardium, a thoracoscopic approach was used in certain studies [21, 22]. Although the authors conclude that the minimally invasive approach using thoracoscopy to harvest the pericardium and an upper ministernotomy or $\mathrm{J}$ ministernotomy for reconstruction might be an alternative to conventional sternotomy, the experience with this strategy is limited to date $[21,22]$.

Furthermore, some centers use bovine or tissue-engineered pericardium instead of autologous pericardium for the construction of the valve [16, 23].

\section{Potential Benefits of the Technique}

\section{Hemodynamic}

The AVNeo using autologous pericardium tends to exactly replicate the anatomy of a normal aortic valve and therefore provides a large effective orifice area (EOA) and very low postoperative gradients (Fig. 1) and Table $1[3-5,6 \bullet, 8$, 11-14, 15•].

They are consistently reported to be remarkably low after AVNeo. Ozaki et al. [6•] report a mean peak gradient of $15.2 \pm$ $6.3 \mathrm{mmHg}$ on average 8 years after surgery. Krane and colleagues [15•] report a mean pressure gradient of $8.9 \pm$ $3.8 \mathrm{mmHg}$ and a large EOA of $2.1 \pm 0.7 \mathrm{~cm}^{2}$ at discharge, which remained stable within the first postoperative year. This is in line with recently published first data from the United Kingdom (UK) with peak and mean transvalvular gradients of $16 \pm 3.7$ and $9 \pm 2.2 \mathrm{mmHg}$ after 12.5 months [13•]. In patients with isolated aortic stenosis, Iida and colleagues report a mean peak pressure gradient of $22 \pm 10.7 \mathrm{mmHg}$ one week after the procedure and $19.2 \pm 9.7 \mathrm{mmHg}$ after 20 months [8]. In our cohort, after median 21 months of followup, median (IQR) mean and peak gradients were $6(5,9)$ $\mathrm{mmHg}$ and $12(8,17) \mathrm{mmHg}$, respectively; these results are similar to recently published data from a US center [12].

Moreover, to confirm the beneficial hemodynamic performance of AVNeo, Krane and colleagues [15•] additionally 


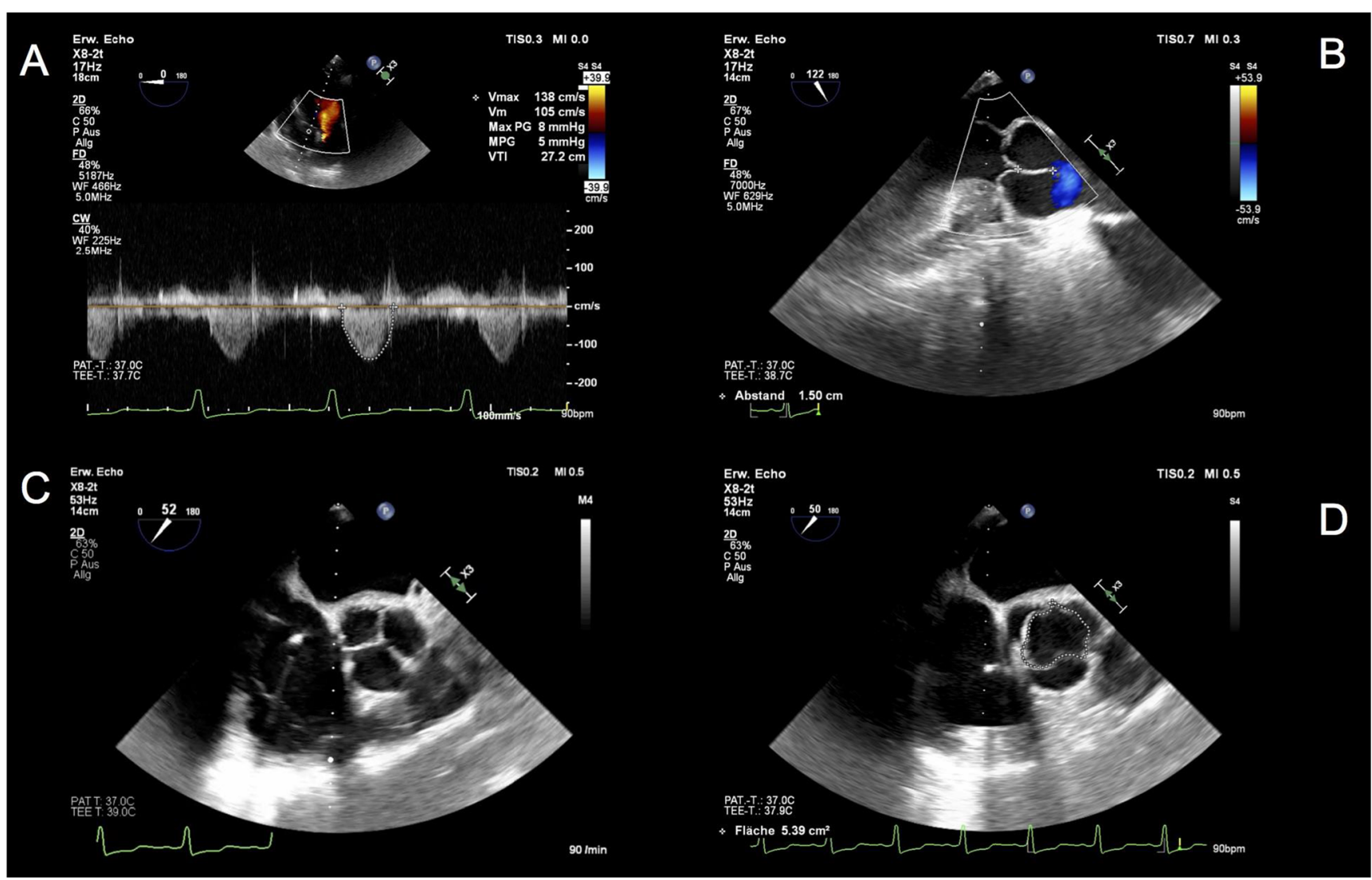

Fig. 1 Intraoperative transesophageal echocardiography following AVNeo using autologous pericardium (OZAKI technique) in a 51-yearold man. Transvalvular mean gradient was $5 \mathrm{mmHg}$, and no valve

measured the annulus diameter with Abbott/St. Jude Trifecta sizers in 71 of 103 patients. This analysis showed a significantly larger EOA and significantly lower mean pressure gradients at discharge in patients undergoing the AVNeo compared with virtually implanted Trifecta bioprosthesis. This underlines the excellent hemodynamic performance of AVNeo [15•].

The beneficial gradients and the large EOA could be of special importance in patients with small annuli. Ozaki et al. found that $75.7 \%$ of their Japanese patients had small aortic annuli. This group of patients had significantly higher postoperative peak pressure gradients shortly after the operation compared with those with larger aortic annuli. However, this significant difference was entirely resolved after a few years of follow-up without any intervention. Since a more natural motion of pericardial cusps has been observed on echocardiography over time, this improvement of hemodynamics might originate from a continuous remodeling of the autologous pericardial cusps $[4,24]$.

\section{Infectious Environment}

The minimal use of foreign material (only sutures) makes AVNeo using autologous pericardium theoretically attractive from an infectious point of view: firstly, insufficiency was detected (A, B). Coaptation height of the anatomical reconstructed aortic valve was $15 \mathrm{~mm}(\mathbf{B}, \mathbf{C})$, and the valve opening area was $5.4 \mathrm{~cm}^{2}$ (D)

regarding the risk of endocarditis and secondly, in case of patients with acute endocarditis.

However, the reported rates of reoperation due to endocarditis in patients who underwent AVNeo variegates in the currently available literature. Ozaki et al. [6•] report 13 reoperations due to endocarditis among 850 patients $(2 \%)$ during an average follow-up period of 53.7 months, whereas Mourad et al. [16] (who have used tissue-engineered pericardium in most operations) report 5 reoperations among 52 patients $(10 \%)$ during an average follow-up period of 11.2 months. In both studies, the need for reoperation was mostly due to endocarditis (Ozaki et al.:13/15; Mourad et al.: 5/5) [6•, $16]$. Iida and colleagues [8] report two cases (4\%) of endocarditis requiring reoperation within 30.4 months follow-up, which is in line with data reported from the UK (5\% endocarditis within a 12.5 months follow-up) [13•]. In the cohorts published by Ngo and colleagues [10] as well as by Krane and colleagues [15•], rates of reoperation for endocarditis were similar (Ngo et al: 1.8\%; Krane et al: $1 \%$ ). In our published cohort, one out of 35 patients (3\%) needed a reoperation during an average follow-up period of 21 months due to endocarditis.

A reasonable comparison of the AVNeo with biological or mechanical prostheses regarding the occurrence of 
Table 1 Benefits and limitations of AVNeo procedure using autologous pericardium

\begin{tabular}{|c|c|c|c|c|c|c|c|c|}
\hline & Hemodynamic & $\begin{array}{l}\text { Infectious } \\
\text { environment }\end{array}$ & $\begin{array}{l}\text { Oral } \\
\text { anticoagulation }\end{array}$ & Pacemaker & $\begin{array}{l}\text { Costs and } \\
\text { availability }\end{array}$ & Durability & Complexity & $\begin{array}{l}\text { Valve-in-valve } \\
\text { procedure }\end{array}$ \\
\hline Benefit/limitation & $\begin{array}{l}\text { Excellent } \\
\text { hemody- } \\
\text { namic } \\
\text { perfor- } \\
\text { mance } \\
\text { through } \\
\text { exactly } \\
\text { replication } \\
\text { of the } \\
\text { anatomy }\end{array}$ & $\begin{array}{l}\text { Minimal use } \\
\text { of foreign } \\
\text { material } \\
\text { makes the } \\
\text { technique } \\
\text { attractive } \\
\text { regarding } \\
\text { the risk of } \\
\text { endocardi- } \\
\text { tis and in } \\
\text { the setting } \\
\text { of acute } \\
\text { endocardi- } \\
\text { tis }\end{array}$ & $\begin{array}{l}\text { Postoperative } \\
\text { antithrom- } \\
\text { botic therapy } \\
\text { consists of } \\
\text { aspirin low } \\
\text { dose (6 } \\
\text { months to } \\
\text { life-long) }\end{array}$ & $\begin{array}{l}\text { Reported } \\
\text { rates for } \\
\text { permanent } \\
\text { peace- } \\
\text { maker } \\
\text { implanta- } \\
\text { tion after } \\
\text { AVNeo } \\
\text { are very } \\
\text { low } \\
(0-0.25 \%)\end{array}$ & $\begin{array}{l}\text { Only few hard } \\
\text { contraindica- } \\
\text { tions restrict } \\
\text { the use of } \\
\text { AVNeo } \\
\text { making this } \\
\text { technique } \\
\text { generally } \\
\text { available }\end{array}$ & $\begin{array}{l}\text { The longest } \\
\text { available } \\
\text { follow-up } \\
\text { so far } \\
\text { provides } \\
\text { a mean } \\
\text { follow-up } \\
\text { period of } \\
53.7 \pm \\
28.2 \\
\text { months }\end{array}$ & $\begin{array}{l}\text { Complexity of } \\
\text { the AVNeo } \\
\text { procedure is } \\
\text { undoubted- } \\
\text { ly higher } \\
\text { compared } \\
\text { to aortic } \\
\text { valve } \\
\text { replacement } \\
\text { associated } \\
\text { with longer } \\
\text { aortic } \\
\text { cross-clamp } \\
\text { time }\end{array}$ & $\begin{array}{l}\text { To the best of } \\
\text { our } \\
\text { knowledge, } \\
\text { experience } \\
\text { with } \\
\text { implanting a } \\
\text { TAVI in an } \\
\text { aortic vave } \\
\text { after } \\
\text { AVNeo is } \\
\text { limited }\end{array}$ \\
\hline Comment & $\begin{array}{l}\text { This could be } \\
\text { of special } \\
\text { interest in } \\
\text { patients } \\
\text { with small } \\
\text { aortic } \\
\text { annuli }\end{array}$ & $\begin{array}{l}\text { Experience } \\
\text { regarding } \\
\text { this topic is } \\
\text { limited, } \\
\text { especially } \\
\text { for the } \\
\text { setting of } \\
\text { acute } \\
\text { endocardi- } \\
\text { tis }\end{array}$ & $\begin{array}{l}\text { Whether heart } \\
\text { valve } \\
\text { thrombosis } \\
\text { becomes an } \\
\text { issue after } \\
\text { AVNeo and } \\
\text { if therefore } \\
\text { early } \\
\text { antithrom- } \\
\text { botic therapy } \\
\text { should be } \\
\text { adapted } \\
\text { must be } \\
\text { analyzed in } \\
\text { the future }\end{array}$ & $\begin{array}{l}\text { This finding } \\
\text { could be } \\
\text { explained } \\
\text { by the } \\
\text { implanta- } \\
\text { tion } \\
\text { technique } \\
\text { of the } \\
\text { newly } \\
\text { construct- } \\
\text { ed leaflets } \\
\text { directly to } \\
\text { the } \\
\text { annulus }\end{array}$ & $\begin{array}{l}\text { The costs of the } \\
\text { single-use } \\
\text { devices nearly } \\
\text { touch the price } \\
\text { for a } \\
\text { prosthesis, and } \\
\text { thus, the } \\
\text { potential cost } \\
\text { savings are } \\
\text { limited }\end{array}$ & $\begin{array}{l}\text { Since the } \\
\text { AVNeo } \\
\text { uses non- } \\
\text { living } \\
\text { tissue, } \\
\text { long-term } \\
\text { durability } \\
\text { is under } \\
\text { question }\end{array}$ & $\begin{array}{l}\text { Longer aortic } \\
\text { cross-clamp } \\
\text { time and } \\
\text { higher } \\
\text { complexity } \\
\text { of the } \\
\text { procedure } \\
\text { seems not to } \\
\text { results in } \\
\text { higher } \\
\text { periopera- } \\
\text { tive } \\
\text { mortality or } \\
\text { morbidity } \\
\text { so far }\end{array}$ & $\begin{array}{l}\text { Whether a } \\
\text { valve-in- } \\
\text { valve } \\
\text { procedure is } \\
\text { feasible and } \\
\text { safe in } \\
\text { patients } \\
\text { after } \\
\text { AVNeo has } \\
\text { to be } \\
\text { determined } \\
\text { in future } \\
\text { studies }\end{array}$ \\
\hline
\end{tabular}

endocarditis is difficult due to the different follow-up periods. In a nationwide population-based cohort study including 26,580 patients after SAVR $(16,426(62 \%)$ received a bioprosthesis and 10,154 (38\%) received a mechanical valve), the incidence of prosthetic valve endocarditis was $0.57 \%$ per person-year [25]. The highest risk was observed during the first year after SAVR $(0.99 \%$ per person-year), and the risk was higher in patients receiving a biological prosthesis than in patients receiving a mechanical prosthesis [25]. In a metaanalytic comparison with other aortic valve substitutes, the incidence of valve-related events in AVNeo (including structural valve degeneration, endocarditis, and reintervention) was similar to the incidence rates of most valve substitutes included in the analysis. Only the Magna Ease bioprosthesis was associated with a lower incidence of reintervention [13•].

For the setting of an acute endocarditis, to the best of our knowledge, no specific data comparing the OZAKI technique with biological or mechanical prostheses are available. However, since no foreign material is used apart from the sutures, it can be assumed (and some case reports provide initial evidence) that from an infectious point of view, the AVNeo could be beneficial in an infectious environment [26, 27].

\section{Oral Anticoagulation}

Ozaki et al. [6] recommend low-dose aspirin for 6 months after the procedure, which was also administered in the cohort of Krane and colleagues [15•]. However, according to our internal guidelines, low-dose aspirin $(100 \mathrm{mg} /$ day $)$ is recommended lifelong, which is in line with the strategy published by the UK study groups $(150 \mathrm{mg} / \mathrm{d}$ lifelong) [13•]. Nevertheless, both strategies are beneficial for the patient compared to the lifelong oral anticoagulation that is necessary after the implantation of a mechanical prosthesis.

Recently, in patients undergoing a transcatheter aortic valve replacement (TAVR) procedure, subclinical transcatheter heart valve thrombosis was increasingly documented in patients who had undergone routine four-dimensional multidetector computed tomography post TAVR [28]. Therefore, following TAVR, dual antiplatelet therapy (DAPT) for 36months post-procedure is recommended by the ESC/ EACTS guidelines, the American Heart Association/ American College of Cardiology (AHA/ACC) guidelines, and the latest TAVR expert consensus statement at the moment. Oral anticoagulation following TAVR is only recommended in case of other indications for anticoagulation such 
as atrial fibrillation $[2,28-30]$. However, recently published data suggest that the incidence of bleeding and the composite of bleeding or thromboembolic events at 1-year follow-up were significantly less frequent with aspirin alone than with aspirin plus clopidogrel administered for 3 months [31].

Whether heart valve thrombosis becomes an issue after AVNeo and if therefore early antithrombotic therapy should be adapted must be analyzed very carefully in the future.

\section{Pacemaker}

The need for permanent pacemaker implantation (PPI) is an intensively discussed topic when comparing aortic valve interventions, especially TAVR versus SAVR, with rates of PPI ranging from 3.7 to $8.8 \%$ after SAVR depending on the type of valve $[32,33]$.

Reported rates for PPI after AVNeo are very low. While Ozaki and colleagues [17] reported of one $(0.25 \%)$ patient out of 404 patients that needed a PPI during the follow-up, no PPI was necessary after isolated AVNeo in Krane et al.'s and our cohort $\left[14^{\bullet}, 15 \bullet\right]$. This finding may be explained by the fact that the newly constructed leaflets are merely implanted into the annulus without any upcoming radial forces. In contrast, implanting a valve prosthesis can lead to mechanical stress and damage to the conduction system, especially in selfexpandable or rapid deployment valves and TAVR $[32,33]$.

Since there are (though conflicting) data suggesting the adverse effects of a postprocedural PPI, especially after TAVR, the low rate of PPI after AVNeo could be an important advantage.

\section{Costs and Availability}

Theoretically, the AVNeo provides the benefit of being ubiquitously available. Since hard contraindications are limited and only include previous thoracic radiation, pericarditis, and re-operation with regard to a potential damage of the pericardium, a wide range of patients is eligible for the AVNeo [5]. This could especially be attractive in countries with limited financial resources. Unfortunately, the reusable templates and sizers have been withdrawn from market and replaced by single-use tools. The costs of the single-use devices nearly touch the price for a prosthesis, and thus, the potential cost savings are limited.

\section{Potential Limitations of the Technique}

\section{Durability}

Even if several new study groups have recently confirmed AVNeo to be a safe and reproducible technique, the key question is durability. Data regarding this are limited to date $[12-13,14 \bullet]$.
In their midterm outcomes, Ozaki and colleagues [6] report freedom from death, cumulative incidence of reoperation, and cumulative incidence of recurrent moderate aortic regurgitation or greater after a mean follow-up period of $53.7 \pm 28.2$ months of $85.9 \%, 4.2 \%$, and $7.3 \%$, respectively. Reoperations were performed in 15 patients ( $0.4 \%$ per patient-year), in 13 of which the reoperation was due to infective endocarditis [6•]. Even in patients with dialysis who are usually prone to early prosthesis failure due to calcification, no calcifications over time were reported. However, the follow-up period in these patients was limited to $25.2 \pm 17.5$ months [4].

On the basis of data from our own research group with a median (IQR) follow-up period of 21 months, we report 1 reoperation out of 35 patients, and this is due to endocarditis 5 months after the initial operation [14•]. The echocardiographic follow-up after median (IQR) 22 months showed no/trace or mild aortic regurgitation in the vast majority of the patients (no/trace: 18 patients $(62 \%)$; mild: 9 patients $(31 \%)$ ). Twenty-seven patients (93\%) showed no aortic valve stenosis, whereas in 2 patients (7\%), a mild aortic valve stenosis was detected. Moderate aortic regurgitation was seen in two patients $(7 \%)$. Median (IQR) mean gradient was $6(5,9)$ $\mathrm{mmHg}$, and median (IQR) peak gradient was $12(8,17)$ mmHg [14•].

Krane and colleagues [15•] report on 4 patients undergoing reoperation; 2 because of early valve insufficiency, one due to endocarditis 6 weeks postoperatively, and 1 patient due to aortic valve insufficiency 2 years after surgery. Freedom from aortic insufficiency $\geq$ grade II at 12 and 24 months was $98.2 \% \pm 0.02 \%$ and $92.1 \% \pm 0.05 \%$, respectively. Mean pressure gradient and EOA were $8.9 \pm 3.8 \mathrm{mmHg}$ and $2.1 \pm 0.7 \mathrm{~cm}^{2}$, respectively, and remained stable within the first year after surgery.

However, since the AVNeo uses non-living tissue, longterm durability is still to be determined [7]. More data is also required regarding potential immunological mechanisms. However, in cases in which autologous pericardium is used, this kind of response is assumed to be rare.

Nevertheless, more long-term data is urgently needed to answer these central questions.

\section{Complexity and Cross-Clamp Time}

Even if AVNeo has a highly standardized operative protocol, the complexity of the procedure is undoubtedly higher compared to aortic valve replacement, and associated with a longer aortic cross-clamp time compared to AVR. For isolated AVNeo, aortic cross-clamp time is reported to last about 80 min, even in minimally invasive procedures using a partial sternotomy $[14 \cdot, 16,32]$.

However, the longer aortic-cross clamp time and the higher complexity of the procedure do not seem to result in higher perioperative mortality or morbidity. In Ozaki's cohort as well 
as in the recently published reports including our group and groups from the UK and the US, perioperative mortality and morbidity were both low and comparable with reported rates after biological valve replacement $[5,6 \bullet, 12-14,15 \bullet, 32]$.

\section{Valve in Valve Procedure}

Transcatheter aortic valve-in-valve implantation for failed surgical biological prostheses is considered a safe, effective, and reproducible therapeutic option for patients at high surgical risk [34]. However, the experience with TAVR in an aortic valve after AVNeo is limited [35]. Due to the large leaflets after AVNeo, coronary occlusion may be a risk and must be addressed specifically. Whether or not a valve-in-valve procedure is feasible and safe in patients after AVNeo has to be determined in future studies. Depending on the durability of the valve, this could become an important factor in the future.

\section{Patient Selection}

In our institution, we consider every patient who is suitable for an AVR using a biological prosthesis or has a contraindication for oral anticoagulation eligible for AVNeo. Whether or not the AVNeo procedure is eventually performed is furthermore thoroughly discussed in the Heart Team and with the patient. Contraindications for the procedure are pericarditis, previous thoracic radiation and re-operation with regard to a potential damage of the pericardium. No technical restrictions can be expected regarding annulus and aortic sinus sizes since a wide range of cusp sizes is available (from $13 \mathrm{~mm}$ to $35 \mathrm{~mm}$ ). Moreover, the AVNeo procedure is also feasible in bicuspid aortic valves. However, guidelines for the treatment of aortic diseases must be considered. It is crucial to discuss the above-mentioned points in detail with the patient for shared decision making. Especially the missing data regarding long-term durability has to be discussed with the patient in detail to prevent wrong expectations. Furthermore, a "bail-out" in case of an unsatisfying result after reconstruction has to be discussed preoperatively.

\section{Outlook}

Despite the growing experience with the AVNeo procedure and an increasing number of recently published results from various study groups around the globe, there is a major unmet need for more data, especially long-term follow-up data and data from randomized controlled trials comparing AVNeo with established prostheses. Krane and colleagues [15•] have initiated a prospective randomized controlled trial (TriRec trial, clinicaltrials.gov: NCT03600662) comparing the AVNeo procedure with the St. Jude Trifecta prosthesis, with the EOA at discharge as primary endpoint. Since secondary endpoints include echocardiographic data as well as a 10-year follow-up, this study will hopefully answer some of the above-discussed questions and help defining the significance of AVNeo in aortic valve surgery.

\section{Conclusion}

In our opinion, AVNeo using autologous pericardium is a promising technique providing excellent hemodynamic results, low rates of permanent pacemaker implantation, and omission of oral anticoagulation.

However, there is a major unmet need for more data especially regarding long-term durability. Therefore, patients should be carefully selected with shared decision making as an obligation.

Abbreviations AVNeo, Aortic valve neocuspidization; AVR, Aortic valve replacement; CABG, Coronary artery bypass graft; EOA, Effective orifice area; IQR, Interquartile range; PPI, Permanent pacemaker implantation; SAVR, Surgical aortic valve replacement; TAVR , Transcatheter aortic valve replacement; TEE, Transesophageal echocardiography

Funding Open Access funding provided by Universität Basel (Universitätsbibliothek Basel).

\section{Declarations}

Conflict of interest The authors declare that there is no conflict of interest.

Open Access This article is licensed under a Creative Commons Attribution 4.0 International License, which permits use, sharing, adaptation, distribution and reproduction in any medium or format, as long as you give appropriate credit to the original author(s) and the source, provide a link to the Creative Commons licence, and indicate if changes were made. The images or other third party material in this article are included in the article's Creative Commons licence, unless indicated otherwise in a credit line to the material. If material is not included in the article's Creative Commons licence and your intended use is not permitted by statutory regulation or exceeds the permitted use, you will need to obtain permission directly from the copyright holder. To view a copy of this licence, visit http://creativecommons.org/licenses/by/4.0/.

\section{References}

Papers of particular interest, published recently, have been highlighted as:

- Of importance

•. Of major importance

1. Nkomo VT, Gardin JM, Skelton TN, Gottdiener JS, Scott CG, Enriquez-Sarano M. Burden of valvular heart diseases: a population-based study. Lancet (London, England). 
2006;368(9540):1005-11. https://doi.org/10.1016/S0140-6736(06) 69208-8.

2. Baumgartner H, Falk V, Bax JJ, de Bonis M, Hamm C, Holm PJ, et al. 2017 ESC/EACTS Guidelines for the management of valvular heart disease. Eur Heart J. 2017;38(36):2739-91. https://doi.org/10. 1093/eurheartj/ehx391.

3. Ozaki S, Kawase I, Yamashita H, Uchida S, Nozawa Y, Matsuyama T, et al. Aortic valve reconstruction using selfdeveloped aortic valve plasty system in aortic valve disease. Interact Cardiovasc Thorac Surg. 2011;12(4):550-3. https://doi. org/10.1510/icvts.2010.253682.

4. Ozaki S, Kawase I, Yamashita H, Uchida S, Takatoh M, Hagiwara $\mathrm{S}$, et al. Aortic Valve Reconstruction Using Autologous Pericardium for Aortic Stenosis. Circ J. 2015;79(July):1504-10. https://doi.org/10.1253/circj.CJ-14-1092.

5. Reuthebuch O, Koechlin L, Schurr U, Grapow M, Fassl J. Eckstein FS. Aortic valve replacement using autologous pericardium: single centre experience with the Ozaki technique Swiss Med Wkly. 2018;148:w14591. https://doi.org/10.4414/smw.2018.14591.

6. Ozaki S, Kawase I, Yamashita H, Uchida S, Takatoh M, Kiyohara N. Midterm outcomes after aortic valve neocuspidization with glutaraldehyde-treated autologous pericardium. J Thorac Cardiovasc Surg. 2018;155(6):2379-87. https://doi.org/10.1016/j. jtcvs.2018.01.087 This article from Ozaki and colleagues present the longest available follow-up data so far of 850 patients with the AVNeo procedure. Freedom from death, cumulative incidence of reoperation, and that of recurrent moderate aortic regurgitation or greater was $85.9 \%, 4.2 \%$, and $7.3 \%$, respectively, with the longest follow-up of 118 months.

7. Sologashvili T, Prêtre R. The place of the Ozaki procedure in the treatment of aortic valve disease. Swiss Med Wkly. 2018;148. https://doi.org/10.4414/smw.2018.14612.

8. Iida Y, Fujii S, Akiyama S, Sawa S. Early and mid-term results of isolated aortic valve neocuspidization in patients with aortic stenosis. Gen Thorac Cardiovasc Surg. 2018;66(11):648-52. https://doi. org/10.1007/s11748-018-0976-0.

9. Sá MPBO, Perazzo ÁM, Zhigalov K, et al. Aortic valve neocuspidization with glutaraldehyde-treated autologous pericardium (Ozaki procedure) - a promising surgical technique. Braz $\mathrm{J}$ Cardiovasc Surg. 2019;34(5):610-4. https://doi.org/10.21470/ 1678-9741-2019-0304.

10. Ngo HT, Nguyen HC. Reconstruction of aortic valve by autologous pericardium ( Ozaki's procedure ): single center experience in Vietnam. 2020;(1). https://doi.org/10.1177/0218492320981468.

11. Iida Y, Sawa S, Fujii S, Shimizu H. Aortic valve neocuspidization in patients under 65 years old. Gen Thorac Cardiovasc Surg. 2020;68(8):780-4. https://doi.org/10.1007/s11748-020-01302-9.

12. Pirola S, Mastroiacovo G, Arlati FG, Mostardini G, Bonomi A, Penza E, et al. Single center five years' experience of Ozaki procedure: midterm follow-up. Ann Thorac Surg. 2021;111:1937-43. https://doi.org/10.1016/j.athoracsur.2020.08.039.

13. Benedetto U, Sinha S, Dimagli A, et al. Aortic valve neocuspidization with autologous pericardium in adult patients: UK experience and meta-analytic comparison with other aortic valve substitutes. Eur J Cardio-Thoracic Surg. 2021;00:1-13. https://doi.org/10.1093/ejcts/ezaa472 This study reports the clinical and echocardiographic outcomes of 55 patients undergoing AVNeo with autologous pericardium in 2 UK centres from 2018 to 2020 . Furthermore, the authors provide a meta-analytic comparison between series on AVNeo versus biological valve prostheses as well as autograft aortic valve.

14. Koechlin L, Schurr U, Miazza J, et al. Echocardiographic and Clinical Follow-up After Aortic Valve Neocuspidization Using Autologous Pericardium. World J Surg. 2020. https://doi.org/10. 1007/s00268-020-05588-x This single center study presents the longest echocardiographic follow-up data (median 22 months) from a centre other than the Toho University Ohashi Medical Centre. In 35 patients with the AVNeo procedure, postoperative gradients were remarkably low and the vast majority of patients showed no/trace or mild aortic regurgitation.

15. Krane M, Boehm J, Prinzing A, Ziegelmueller J, Holfeld J, Lange R. Excellent Hemodynamic Performance After Aortic Valve Neocuspidization Using Autologous Pericardium. Ann Thorac Surg. 2020. https://doi.org/10.1016/j.athoracsur.2020.04.108 In their large cohort of 103 patients, Krane and colleagues present their clinical and echocardiographic data (12 months follow-up). Furthermore, during AVNeo surgery, valve sizing for an Abbott/St Jude Trifecta bioprosthesis (virtually implanted Trifecta bio- prosthesis; St Jude Medical, St Paul, MN) was performed to compare pressure gradients and effective orifice area with published data.

16. Mourad F, Shehada SE, Lubarski J, Serrano M, Demircioglu E, Wendt $\mathrm{D}$, et al. Aortic valve construction using pericardial tissue: short-term single-centre outcomes $\dagger$. Interact Cardiovasc Thorac Surg. 2019;28(2):183-90. https://doi.org/10.1093/icvts/ivy230.

17. Ozaki S, Kawase I, Yamashita H, Uchida S, Nozawa Y, Takatoh M, et al. A total of 404 cases of aortic valve reconstruction with glutaraldehyde-treated autologous pericardium. J Thorac Cardiovasc Surg. 2014;147(1):301-6. https://doi.org/10.1016/j.jtcvs.2012.11. 012.

18. Duran CMG, Gometza B, Kumar N, Gallo R, Martin-Duran R. Aortic valve replacement with freehand autologous pericardium. J Thorac Cardiovasc Surg. 1995;110:511-6. https://doi.org/10.1016/ S0022-5223(95)70248-2.

19. Chan KMJ, Rahman-Haley S, Mittal TK, Gavino JA, Dreyfus GD. Truly stentless autologous pericardial aortic valve replacement: an alternative to standard aortic valve replacement. J Thorac Cardiovasc Surg. 2011;141:276-83. https://doi.org/10.1016/j. jtcvs.2010.09.038.

20. Koechlin L, Isu G, Borisov V, Robles Diaz D, Eckstein FS, Marsano A, et al. Impact on mechanical properties of 10 versus 20 minute treatment of human pericardium with glutaraldehyde in OZAKI procedure. Ann Thorac Cardiovasc Surg. 2021. https://doi. org/10.5761/atcs.nm.20-00125.

21. Rosserkin EV, Kobzev EE, Bazylev VV. Minimally invasive Ozaki technique. Angiol Vasc Surg. 2019;25(3):142. https://doi.org/10. 33529/angi02019319.

22. Nguyen DH, Vo AT, Le KM, et al. Minimally invasive Ozaki procedure in aortic valve disease. Innov Technol Tech Cardiothorac Vasc Surg. 2018;13(5):332-7. https://doi.org/10. 1097/IMI.0000000000000556.

23. Sheng W, Zhao G, Chao Y, Sun F, Jiao Z, Liu P, et al. Aortic valve replacement with bovine pericardium in patients with aortic valve regurgitation a single-center experience. Int Heart J. 2019;60(6): 1344-9. https://doi.org/10.1536/ihj.18-695.

24. Iida Y, Akiyama S, Shimura K, Fujii S, Hashimoto C, Mizuuchi S, et al. Comparison of aortic annulus dimensions after aortic valve neocuspidization with those of normal aortic valve using transthoracic echocardiography. Eur J Cardio-Thoracic Surg. 2018;54(6): 1081-4. https://doi.org/10.1093/ejcts/ezy190.

25. Glaser N, Jackson V, Holzmann MJ, Franco-Cereceda A, Sartipy U. Prosthetic valve endocarditis after surgical aortic valve replacement. Circulation. 2017;136(3):329-31. https://doi.org/10.1161/ CIRCULATIONAHA.117.028783.

26. Ngo HT, Nguyen TT, Nguyen HC, Camilleri L, Thanh LN, Doan HQ. Bicuspid reconstruction surgery in a patient suffering from aortic valve infective endocarditis with annular abscess using Ozaki's procedure: A case report. Int J Surg Case Rep. 2020;76: 266-9. https://doi.org/10.1016/j.ijscr.2020.09.197.

27. Okada K, Inoue Y, Haida H, Suzuki S. Aortic valve reconstruction using autologous pericardium (Ozaki procedure) for active infective 
endocarditis: a case report. Gen Thorac Cardiovasc Surg. 2017;66: 1-3. https://doi.org/10.1007/s11748-017-0875-9.

28. Ng ACT, Holmes DR, Mack MJ, Delgado V, Makkar R, Blanke P, et al. Leaflet immobility and thrombosis in transcatheter aortic valve replacement. Eur Heart J. 2020;41:3184-97. https://doi.org/ 10.1093/eurheartj/ehaa542.

29. Nishimura RA, Otto CM, Bonow RO, Carabello BA, Erwin JP III, Guyton RA, et al. 2014 AHA/ACC guideline for the management of patients with valvular heart disease: executive summary :a report of the american college of cardiology/american heart association task force on practice guidelines. Circulation. 2014;129:2440-92. https://doi.org/10.1161/CIR.0000000000000029.

30. Otto CM, Kumbhani DJ, Alexander KP, Calhoon JH, Desai MY, Kaul S, et al. 2017 ACC Expert consensus decision pathway for transcatheter aortic valve replacement in the management of adults with aortic stenosis. J Am Coll Cardiol. 2017;69:1313-46. https:// doi.org/10.1016/j.jacc.2016.12.006.

31. Brouwer J, Nijenhuis VJ, Delewi R, Hermanides RS, Holvoet W, Dubois CLF, et al. Aspirin with or without clopidogrel after transcatheter aortic-valve implantation. N Engl J Med. 2020;383:144757. https://doi.org/10.1056/nejmoa2017815.

32. Ensminger S, Fujita B, Bauer T, Möllmann H, Beckmann A, Bekeredjian R, et al. Rapid deployment versus conventional bioprosthetic valve replacement for aortic stenosis. J Am Coll Cardiol. 2018;71:1417-28. https://doi.org/10.1016/j.jacc.2018.01. 065 .

33. Fujita B, Schmidt T, Bleiziffer S, Bauer T, Beckmann A, Bekeredjian R, et al. Impact of new pacemaker implantation following surgical and transcatheter aortic valve replacement on 1year outcome. Eur J Cardio-Thoracic Surg. 2020;57:151-9. https://doi.org/10.1093/ejcts/ezz168.

34. Raschpichler MC, Woitek F, Chakravarty T, Flint N, Yoon SH, Mangner N, et al. Valve-in-valve for degenerated transcatheter aortic valve replacement versus valve-in-valve for degenerated surgical aortic bioprostheses: a 3-center comparison of hemodynamic and 1year outcome. J Am Heart Assoc. 2020;9(14):e013973. https://doi. org/10.1161/JAHA.119.013973.

35. Tada N, Tanaka N, Abe K, Hata M. Transcatheter aortic valve implantation after aortic valve neocuspidization using autologous pericardium: a case report. Eur Hear J - Case Reports. 2019;3:3(3). https://doi.org/10.1093/ehjcr/ytz105.

Publisher's Note Springer Nature remains neutral with regard to jurisdictional claims in published maps and institutional affiliations. 